\title{
ANALYSIS OF BIOLOGICAL PRETREATMENT OF RAPESEED STRAW WITH WHITE ROT FUNGI FOR ENZYMATIC HYDROLYSIS
}

\author{
Rasool Ghasemzadeh ${ }^{1}$, Mohammad Taghi Hamed Mosavian $^{1, \$}$, Afzal Karimi $^{2}$
}

\begin{abstract}
The effect of biological pretreatment on the rapeseed straw was evaluated by solid-state cultivation of white rot fungi Phanerochaete chrysosporium. P.chrysosporium degraded the lignin during the pretreatment, with enzymatic hydrolysis ratios increasing in the pretreated straw (3-fold after a 15 day pretreatment). The samples were identified by XRD, FTIR and SEM. X-ray analysis showed that pretreated samples had higher crystallinity than untreated samples $(39,47 \%$ for a pretreated sample compared to $33,17 \%$ for untreated samples) and FTIR spectroscopy demonstrated that the content of lignocellulose also decreased during the biological pretreatment process. The surface characterization study showed morphological changes in pretreated samples. Moreover, the biological pretreatment slowed a plunge in hydrolysis rate during enzymatic hydrolysis.
\end{abstract}

Keywords: Cellulose, delignification, hemicellulose, Phanerochaete chrysosporium, reducing sugar.

\section{INTRODUCTION}

The third widely used oil in the world is rapeseed (Brassica napus) oil. In recent years, there has been a significant increase in the application of rapeseed oil to produce biodiesel. According to FAO (2016), rapeseed was cultivated in over 36 million hectares farms around the world in 2014 with Iran's share being about 160000 hectares. After harvesting and separating rapeseed seeds, agricultural residues are usually burned. Due to its lignocellulosic nature, the rapeseed straw can be utilized for fuel ethanol production via a biochemical process. This process includes pretreatment, enzymatic hydrolysis, and fermentation. Enzymatic hydrolysis is an important step in changing lignocellulosic materials into biofuel (Dionisi et al. 2015).

The resistant structure of lignin restricts the decomposition of the lignocellulosic materials and their conversion into ethanol (Kumar et al. 2006, Lu et al. 2009). Pretreatment methods are mainly based on physico-chemical technologies which involve the use of hot water (Zeng et al. 2011, López-Linares et al. 2014), heat treatment (Boonstra et al. 2006), diluted and concentrated acids (Margeot et al. 2009, Geddes et al. 2010, Li et al. 2013) and alkaline (Li et al. 2010, Yamashita et al. 2010, Tozluoglu 2016).

\footnotetext{
${ }^{1}$ Chemical Engineering Department, Faculty of Engineering, Ferdowsi University of Mashhad, Mashhad, Iran. ${ }^{2}$ Department of Biotechnology, Faculty of Advanced Technologies in Medicine, Iran University of Medical Sciences, Tehran, Iran.

"Corresponding author: mosavian@um.ac.ir

Received: 16.08.2017 Accepted: 18.03.2018
} 
Nevertheless, these processes usually require high temperature and operating pressure. Generally, these pretreatments have major drawbacks: (a) the equipment needs to be resistant against corrosion and pressure, (b) most of these processes require the production of environmentally high-risk effluent and (c) they have massive energy consumption (Singh and Chen 2008).

The biological pretreatment by microorganisms and their enzyme systems can degrade lignin and hemicellulose that are already in existence in the lignocellulosic materials at low energy consumption and under mild environmental conditions (Sun and Cheng 2002, Yu et al. 2009, Bari et al. 2018). White rot fungi are a group of basidiomycetes with unique ability to degrade the structure of lignin and carbohydrates (Yu et al. 2010, Salvachúa et al. 2011, Nazarpour et al. 2013, Camarero et al. 2014). These fungi can decompose lignocellulosic materials via the production of two enzymatic systems: (a) hydrolytic system, which produces cellulases and hemicellulases that degrade polysaccharides and (b) oxidative lignolytic system which degrades lignin and opens the phenyl rings. Lignin Peroxidase (LiP), Manganese Peroxidase (MnP) and laccase are the most important of these enzymes (Kumar et al. 2006, Yu et al. 2009, Castoldi et al. 2014, Yao and Nokes 2014, Ansari et al. 2016). White rot fungi can produce all or part of these enzymes (Yu et al. 2009, Yao and Nokes 2014). Several white rot fungi, such as Phanerochaete chrysosporium, Dichomitus squalens, Ceriporiopsis subvermispora, Pleurotus ostreatus and Coriolus versicolor have been used for biological pretreatment of biomass. The lignin loss of their cultivation was $10-37 \%$ and up to $58 \%$ cellulose was degraded; however, only low saccharification ratios $(35-40 \%)$ were obtained when compared to the saccharification ratios by chemical and physical pretreatment (Itoh et al. 2003, Taniguchi et al. 2005, Zhang et al. 2007). P.chrysosporiumis one of main candidates used by researchers in several pretreatments (Kumar et al. 2006, Sendich et al. 2008, Shrestha et al. 2008, Lu et al. 2009, Singh et al. 2011, Zhang et al. 2012). The main goal of the present study is the solid-state fermentation of rapeseed straw by P.chrysosporium without using any nutrient. The biodegradation patterns of the pretreated straw were also evaluated by chemical component losses, Fourier Transform Infrared (FTIR), Scanning Electron Microscopy (SEM) and X-ray Diffraction Analysis (XRD).

\section{EXPERIMENTAL}

\section{Biomass and microorganism}

The rapeseed straw was supplied by rapeseed farms in Quchan, Khorasan Razavi Province, Iran in the 2011 crop year. To remove soil particles and unwanted materials, the rapeseed straw was washed with water and dried in laboratory environment. Then, it was oven dried at $60^{\circ} \mathrm{C}$ for $24 \mathrm{~h}$ to reach a constant weight. The dried rapeseed straw was grounded, passed through an 18-mesh sieve, packed in nylon containers for further use and stored at room temperature.

The lyophilized P.chrysosporium (ATCC 24725) was purchased from Iranian Regional Center for Collection of Industrial Fungi and Bacteria. The organism was propagated on potato dextrose agar (PDA) plates at $30^{\circ} \mathrm{C}$ for one week and the spores were preserved in dark at $4^{\circ} \mathrm{C}$. Spore suspensions were prepared by washing the agar surface by distilled water and were then diluted so that an absorbance of 0,5 at $650 \mathrm{~nm}$ was obtained in a $1 \mathrm{~cm}$ path length cuvette, as suggested by Sedighi et al. 2009. There were $2 \times 10^{6}$ spores per $\mathrm{ml}$ of the suspension solution. To ensure the appropriate function of the fungus, a new culture medium was prepared every two months.

\section{Biological pretreatment by P.chrysosporium}

In the first step, $5 \mathrm{~g}$ of the rapeseed straw was placed into a capped $250 \mathrm{ml}$ jar and sterilized in the autoclave at $121^{\circ} \mathrm{C}$ for $15 \mathrm{~min}$ and then left to cool down at room temperature. A $2,5 \mathrm{ml}$ of the spore suspension was added to the jar, and moisture of the medium was increased to $80 \% \frac{w \text { water }}{w \text { total }}$ using sterile

distilled water. The cultures were capped and incubated at $37^{\circ} \mathrm{C}$ for 5,10 and 15 days. All cultures were grown in triplicate. In all cases, the rapeseed straw treated in the same conditions without fungal inoculation was used as the control. 


\section{Enzymatic hydrolysis}

Enzymatic hydrolysis was performed in $250 \mathrm{ml}$ of Erlenmeyer flask with $1 \mathrm{~g}$ of the pretreated sample and $100 \mathrm{ml}$ of $0,05 \mathrm{M}$ sodium citrate buffer. A certain amount of cellulase $(10 \mathrm{FPU} / \mathrm{g}$, from Sigma) was added to each flask and the reaction mixtures were incubated in the shaker incubator at $50^{\circ} \mathrm{C}$ and $150 \mathrm{rpm}$ for a maximum of $56 \mathrm{~h}$. Each time point was analyzed for reducing sugar in the triplicate and an average value was reported.

\section{Determination of reducing sugar}

The total reducing sugar was determined by 3,5-dinitrosalicylic acid (DNS) method using glucose as the standard (Miller 1959). A $0,1 \mathrm{ml}$ of the enzymatic hydrolysis solution and $0,9 \mathrm{ml}$ of distilled water were poured into the test tube and then $3 \mathrm{ml}$ of DNS solution was added to the tube. The mixture was placed in a hot water bath for $5 \mathrm{~min}$ and cooled down to room temperature. Then, $7 \mathrm{ml}$ of distilled water was added to the tube, and the absorption occurred at wavelength of $540 \mathrm{~nm}$. The absorbance readings were then converted into equivalent sugar concentration $(\mathrm{mg} / \mathrm{ml})$ using a standard glucose curve. The hydrolysis ratio was calculated using Equation 1:

$$
\text { Hydrolysis ratio }(\%)=\frac{\text { Amount of reducing sugar produced } x 0,9}{\text { Amount of cellulose }+ \text { amount of hemicellulose }} \times 100
$$

\section{Chemical analysis of rapeseed straw}

Rapeseed straw was dried at $60^{\circ} \mathrm{C}$ to reach a constant weight. Neutral Detergent Fiber (NDF), Acid Detergent Fiber (ADF), and Acid Detergent Lignin (ADL) were determined based on the procedure proposed by Van Soest 1963. The amount of hemicelluloses, cellulose and Klason lignin were calculated by measuring the difference between NDF and ADF content, ADF and ADL content and ADL and ash content, respectively. The detail process was as follows:

About $1 \mathrm{~g}$ of dried rapeseed straw and $100 \mathrm{ml}$ of neutral detergent solution with Sodium lauryl Sulfate (SDS) and disodium Ethylene Diamine Tetra Acetate (EDTA) were added into a flask to determine NDF. The mixture was then heated to reach the boiling point within 5-10 min and was boiled for one hour. Then, the hot mixture was filtered; the residues were washed with a minimum of $500 \mathrm{ml}$ of hot distilled water and $10 \mathrm{ml}$ of acetone and dried at $105^{\circ} \mathrm{C}$ to reach a constant weight. The amount of NDF was determined by Equation 2:

$$
N D F(\%)=\frac{\text { Weight of dried residue after treatment with neutral detergent solution }}{\text { Sample weight }} \times 100
$$

Acid detergent solution and Cetyl Tri-methyl Ammonium Bromide (CTAB) and 0,5 $\mathrm{M} \mathrm{H}_{2} \mathrm{SO}_{4}$ were used to determine ADF (Equation 3) in a similar way to NDF determination.

$$
A D F(\%)=\frac{\text { Weight of dried residue after treatment with acid detergent solution }}{\text { Sample weight }} \times 100
$$

For the determination of ADL, the solid material obtained from ADF was digested with $72 \% \mathrm{H}_{2} \mathrm{SO}_{4}$ for $3 \mathrm{~h}$ and then filtered. The residue was completely washed by hot distilled water until it was acid free in $\mathrm{pH}$ paper. The residue was dried at $105^{\circ} \mathrm{C}$ to reach a constant weight (Equation 4). 


$$
A D L(\%)=\frac{\text { Weight of dried residue after treatment with } 72 \% \text { sulphuric acid }}{\text { Sample weight }} \times 100
$$
$5)$.

The ash was determined as the residue after treatment in the muffle at $600{ }^{\circ} \mathrm{C}$ for $24 \mathrm{~h}$ (Equation

$$
\operatorname{Ash}(\%)=\frac{\text { Ash weight }}{\text { Sample weight }} \times 100
$$

\section{X-ray diffraction analysis}

The Crystallinity Index (CrI) of untreated and treated rapeseed straw by P.chrysosporium was collected by an X-ray diffractometer in a BRUKER (Germany). All samples were scanned in the range of $2 \theta=0-40^{\circ}$ at a speed of $1 \% \mathrm{~min}$ at $40 \mathrm{kV}$ and $40 \mathrm{~mA}$. The radiation used was $\mathrm{Cu}(1,54 \AA)$ and $\mathrm{CrI}$ was calculated according to Equation 6:

$$
\text { Crystallinity Index }(\mathrm{Crl}) \%=\frac{I_{002}-I_{a m}}{I_{002}} \times 100
$$

Where $\mathrm{I}_{002}$ is the maximum intensity of peaks at $2 \theta$ between 22 and $23^{\circ}$, and $\mathrm{I}_{\mathrm{am}}$ is the minimum intensity of peaks in $2 \theta$ between 18 and $19^{\circ}$ (Segal et al. 1959).

\section{Fourier Transform Infrared spectroscopy (FTIR) analysis}

The FTIR spectra were obtained from direct transmittance using the $\mathrm{KBr}$ pellet technique through a Perkin Elmer 100 FTIR spectrometer. All spectra $\left(4000-400 \mathrm{~cm}^{-1}\right)$ were measured at a resolution of $4 \mathrm{~cm}^{-1}$ and 64 scans per sample.

\section{Scanning Electron Microscopy (SEM) analysis}

Scanning Electron Microscopy (SEM) was used to study the structural changes of rapeseed straw after biological pretreatment. The samples were dried and coated with gold. The SEM images were taken with a LEO $1450 \mathrm{VP}$ microscope at $15 \mathrm{kV}$.

\section{Data treatment}

Equation 7, an empirical model (Ohmine et al. 1983) was used for data treatment of enzymatic hydrolysis.

$$
X=\frac{1}{k} \ln \left(1+V_{0} k t\right)
$$


Where $\mathrm{X}=$ hydrolysis ratio $(\%), \mathrm{V}_{0}=$ initial hydrolysis rate $(\% / \mathrm{h}), \mathrm{t}=$ hydrolysis time and $\mathrm{k}=$ the rate constant for the retardation process.

According to Equation 7, $\mathrm{V}_{0}$ and $\mathrm{k}$ were determined by regression analysis of the experimental results. Data fit was performed by MATLABR2013a software.

\section{Selectivity value}

Selectivity value is the ratio of lignin degradation to cellulose reduction and it was calculated according to Equation 8:

$$
\text { Selectivity value }=\frac{\text { Lignin loss }}{\text { Cellulose loss }}
$$

\section{RESULTS AND DISCUSSION}

\section{The effect of biological pretreatment on rapeseed straw chemical composition}

Lignin is an important compound found in plant cell walls that limits chemical and biological decomposition and hydrolysis. The reduction of lignin content leads to the exposure of the crystalline structure of cellulose and facilitates substrate access by hydrolytic enzymes (Sun and Cheng 2002). The effect of biological pretreatment on the rapeseed straw after cultivation with P.chrysosporium is shown in Table 1. All components declined over time. In this study, compounds of the rapeseed straw included lignin $(23,9 \%)$, cellulose $(35,08 \%)$, and hemicelluloses $(33,83 \%)$. The largest amount of lignin degradation was observed after 15 days $(6,18 \%)$. This level of lignin removal can be attributed to the maximum production of lignolytic enzymes atthe15th day (Ghasemzadeh et al. 2015). The results are in line with previous studies in which biological pretreatment of lignocellulosic materials had been investigated by white rot fungi (Xu et al. 2010, Singh et al. 2011, Deswal et al. 2014).

Table 1. Losses of different components of the rapeseed straw pretreated by P. chrysosporium*.

\begin{tabular}{|c|c|c|c|c|}
\hline \multirow{2}{*}{$\begin{array}{c}\text { Pretreatment } \\
\text { time (day) }\end{array}$} & \multirow{2}{*}{ Selectivity } & \multicolumn{3}{|c|}{ Component loss (\%) } \\
\cline { 3 - 5 } & 1,17 & $1,08 \pm 0,32$ & $0,92 \pm 0,72$ & $2,63 \pm 0,22$ \\
\hline 5 & 1,48 & $4,36 \pm 0,71$ & $2,94 \pm 0,38$ & $6,44 \pm 0,34$ \\
\hline 10 & 1,83 & $6,18 \pm 0,56$ & $3,37 \pm 0,41$ & $7,27 \pm 0,53$ \\
\hline 15 & & &
\end{tabular}

*Results show the mean value of three replicates \pm standard deviation.

Given that the purpose of this study was pretreatment of rapeseed straw without any nutrient, the resulted values of lignin, cellulose and hemicellulose degradation and also the enzymatic hydrolysis of pretreated straw were less than similar studies which have mostly used more time, nutrients and so on. Certainly, the type of biomass, pre-treatment time and type of the microorganism are very effective factors. Different studies by other researchers are shown in Table 2.

The ratio of lignin degradation to cellulose reduction (selectivity value) can be considered as a function of delignification efficiency. That is, high selectivity implies good prospects for preferential delignification whereas low selectivity indicates massive removal of cellulose during pretreatment (Nazarpour et al. 2013). Selectivity value was used to evaluate the selective lignin-degrading ability. As shown in Table 1, selectivity values rose with an increase in the pretreatment time and it reached its maximum on the 15 th day $(1,83)$. Nevertheless, some reports suggest that selectivity values drop 
with increased pretreatment time. Also, non-selective degradation occurred with an increase in the pretreatment time (Ferraz et al. 2000, Yu et al. 2009, Nazarpour et al. 2013). This subject was not investigated in the present study.

Table 2. Component losses of some feedstocks pretreated by white rot fungi.

\begin{tabular}{|c|c|c|c|c|c|}
\hline Microorganism & $\begin{array}{l}\text { Lignin } \\
\text { loss (\%) }\end{array}$ & $\begin{array}{l}\text { Hemicellulose } \\
\text { loss }(\%)\end{array}$ & $\begin{array}{l}\text { Cellulose } \\
\text { loss }(\%)\end{array}$ & Biomass & Ref. \\
\hline $\begin{array}{l}\text { C. subvermispora } \\
\qquad \begin{array}{c}\text { (90 day) } \\
\text { T. versicolor } \\
\text { (90 day) }\end{array}\end{array}$ & 45,06 & 42,08 & 9,50 & Rubberwood & (Nazarpour et al. 2013) \\
\hline $\begin{array}{c}\text { P. chrysosporium } \\
\text { (14 day) }\end{array}$ & 35,053 & 60,05 & 43,26 & Cotton stalk & (Shi et al. 2009) \\
\hline $\begin{array}{c}\text { Irpex lacteus } \\
\text { (150 day) }\end{array}$ & 68,42 & 76,92 & 76,71 & Corn stover & (Xu et al. 2010) \\
\hline $\begin{array}{c}\text { Pleurotus florida } \\
\text { (60 day) }\end{array}$ & 36 & 45,90 & 18,30 & Corn straw & (Zhong et al. 2011) \\
\hline $\begin{array}{l}\text { Trametes hirsute yj9 } \\
\qquad \begin{array}{l}\text { (14 day) } \\
\text { (28 day) } \\
\text { (42 day) }\end{array}\end{array}$ & $\begin{array}{l}41,74 \\
59,50 \\
71,99\end{array}$ & $\begin{array}{l}52,93 \\
71,40 \\
77,84\end{array}$ & $\begin{array}{l}11,97 \\
27,26 \\
34,06\end{array}$ & Corn stover & (Sun et al. 2011) \\
\hline
\end{tabular}

\section{Characterization of pretreated rapeseed straw}

The FTIR spectroscopy of the pretreated rapeseed straw (15th day) and untreated straw (0th day) is shown in Figure 1. A strong hydrogen bonded $(\mathrm{O}-\mathrm{H})$ stretching absorption is observed at around $3420 \mathrm{~cm}^{-1}$, while bonds at 2920 and $2850 \mathrm{~cm}^{-1}$ represent $\mathrm{C}-\mathrm{H}$ anti-symmetric and symmetric stretching, respectively. Moreover, the existing peaks of $1800-700 \mathrm{~cm}^{-1}$ indicate the following bonds: $1640 \mathrm{~cm}^{-1}$ for absorbed O-H and conjugated C-O; $1440 \mathrm{~cm}^{-1}$ for destroyed C-H in lignin; $1380 \mathrm{~cm}^{-1}$ for C-H deformation in cellulose and hemicellulose; $898 \mathrm{~cm}^{-1}$ for $\mathrm{C}-\mathrm{H}$ deformation in cellulose and peaks between 1200 and $1000 \mathrm{~cm}^{-1}$ represent $\mathrm{C}-\mathrm{O}$ stretching and deformation in cellulose, lignin, and residual hemicellulose bonds (Zhang et al. 2012, Nazarpour et al. 2013). There are many similarities between FTIR spectra of the pretreated rapeseed straw by P.chrysosporium (15th day) and the untreated rapeseed straw (0th day), which indicate the selective removal of carbohydrate components. The intensity of absorption has considerably reduced with an increase in the pretreatment time, indicating the solubilization of constituents of lignocelluloses fraction. The elimination or reduction of absorption intensity at peaks of 1060, 1160 and $898 \mathrm{~cm}^{-1}$ with increased pretreatment time indicate the possibility of destroying lignocellulosic structure with an increase in time. According to FTIR spectra, the permitted incubation period for fungal treatment should be increased to facilitate solubility of lignocellulose and further breakdown. 


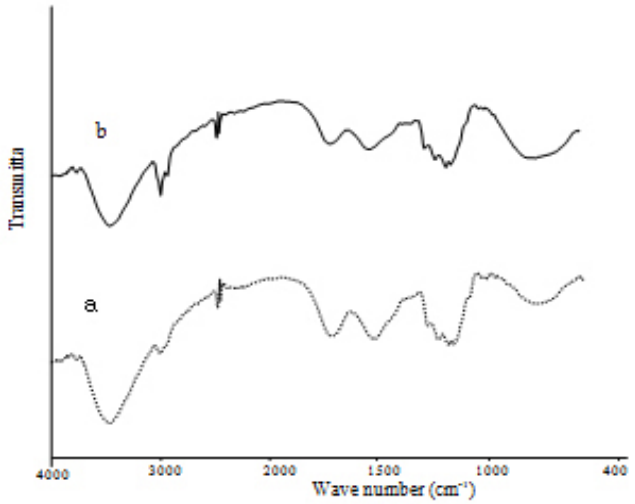

Figure 1. FTIR spectra of rapeseed straw before and after pretreatment by P.chrysosporium: (a) Before pretreatment (...), (b) 15 days after pretreatment (-).

The main compounds of lignocellulosic biomasses are cellulose, hemicellulose and lignin, with cellulose being surrounded by lignin and hemicelluloses (Sun and Cheng 2002, Chandra et al. 2007). Hemicellulose and lignin are amorphous components, while cellulose is considered to be a crystalline component (Nazarpour et al. 2013). Given the impossibility of complete separation of cellulose from other components of fibers, the direct measurement of cellulose crystallinity in biomass is not possible (Zhao et al. 2008). Currently, the measurement of crystallinity index by X-ray is the best way of estimating the effectiveness of pretreatment in the crystallinity of biomass (Kumar et al. 2009). The intensities of amorphous and crystalline regions were measured at $2 \theta\left(18^{\circ}\right)$ and $2 \theta\left(22\right.$ and $\left.23^{\circ}\right)$, respectively. Table 3 shows the crystallinity index for untreated and pretreated rapeseed straw by P.chrysosporium. As can be seen, the crystallinity index increased during pretreatment time so that after 15 days it reached $39,47 \%$, whereas this figure was $33,17 \%$ in the untreated rapeseed straw. The increased crystallinity index might be attributed to the degradation and modification of hemicellulose and lignin, as reported in previous studies (Kim and Lee 2005, Jeoh et al. 2007, Nazarpour et al. 2013). Therefore, the augmented crystallinity index in pretreated samples suggests greater exposure of cellulose after biological pretreatment. This has been discussed in a number of previous reports (Zhang et al. 2012, Nazarpour et al. 2013).

Table 3. Crystallinity Index of untreated and fungal-treated rapeseed straw by P.chrysosporium.

\begin{tabular}{|l|l|l|l|}
\hline \multirow{2}{*}{ Samples } & \multicolumn{3}{|c|}{ CrI (\%) } \\
\cline { 2 - 4 } & 5 days & 10 days & 15 days \\
\hline Untreated & 33,17 & 33,17 & 33,17 \\
\hline Fungal treated & 34,23 & 37,15 & 39,47 \\
\hline
\end{tabular}

The morphologies of samples before and after pretreatment were examined by SEM. As shown in Figure 2, the untreated rapeseed straw had a compact structure with a smooth flat surface area and a partial porosity, while the fungal-pretreated rapeseed straw had a partially broken or degraded face and many small pores and sponge-like structures were observed after pretreatment by P.chrysosporium. By hand-touching, it was found that the pretreated rapeseed straw was significantly softer and looser than the untreated ones. This conversion could be due to fungal growth or effects of extracellular enzymes secreted by the fungus. The structural changes of fungal-pretreated rapeseed straw can provide larger accessible surface area for the enzymatic hydrolysis and result in enhanced digestibility of the pretreated 
substrate.
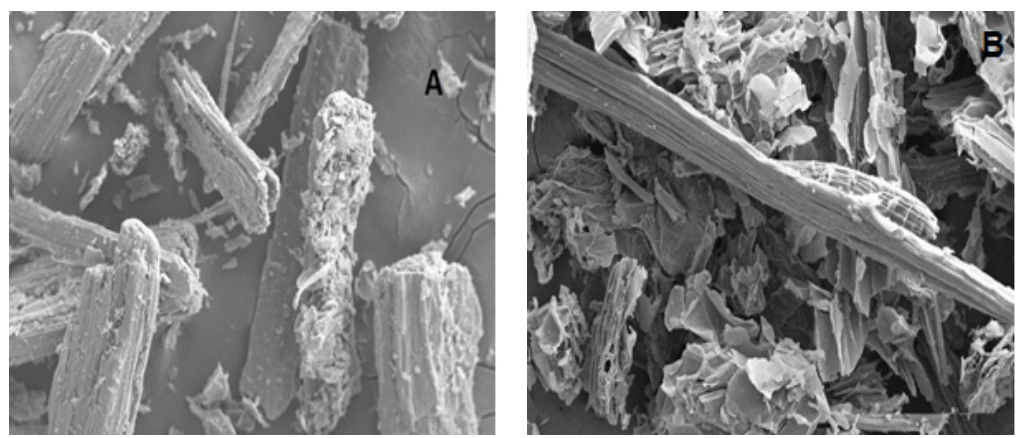

Figure 2. SEM images of the rapeseed straw before and after pretreatment: A) untreated and B) pretreated by P.chrysosporium after15 days.

\section{Enzymatic hydrolysis of rapeseed straw}

To evaluate the effect of pretreatment by P.chrysosporium on the enzymatic hydrolysis of pretreated rapeseed straw, hydrolysis ratio was determined after enzymatic hydrolysis for 0-56 h (Figure 3). As can be seen, the untreated rapeseed straw was more resistant to enzymatic hydrolysis, yielding a hydrolysis ratio of $2,2 \%$ after $56 \mathrm{~h}$ of hydrolysis. The hydrolysis ratio increased with the pretreatment time. The highest hydrolysis ratio of the pretreated rapeseed straws after 5, 10, and 15 days were 3,6 ; 4,8 ; and $6,6 \%$, respectively. The results indicate that the enzymatic hydrolysis is significantly affected by the pretreatment time. As the pretreatment time increases, delignification and hemicellulose removal is intensified, leading to greater availability of enzymes to cellulose and consequently improved digestibility of the cellulose (Öhgren et al. 2007, Nazarpour et al. 2013).

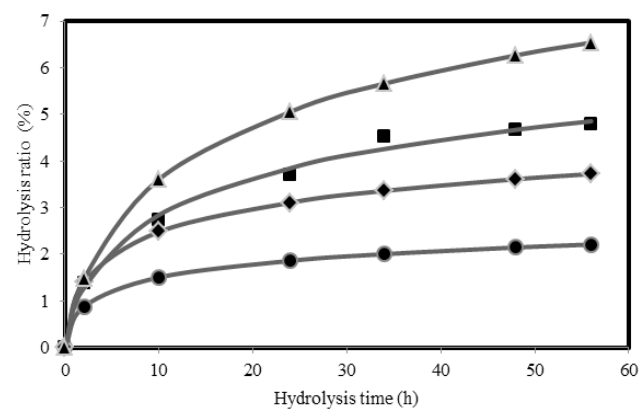

Figure 3. Time course of hydrolysis ratio (\%) during the hydrolysis of rapeseed straw (a) untreated $(\bullet)$ and (b) pretreated by P.chrysosporiumafter5 (४), $10(\bullet)$ and 15 ( $\triangle$ ) days.

Equation 7 was used to characterize hydrolysis kinetics by regression analysis of the experimental data. As shown in Figure 3 (dotted curve), a good agreement with the experimental results was observed in the regression curves. According to Table 4, the biological pretreatment of rapeseed straw by P.chrysosporium increased the initial hydrolysis rate $\mathrm{V}_{0}$ on the 5 th day. After 5 days of pretreatment, there was a 1,38-fold increase in the initial hydrolysis rate $\mathrm{V}_{0}$, but it began to decline with increased pretreatment time. However, the rate constant for the retardation process $(\mathrm{k})$ dropped after the pretreatment, such that after 15 days, $\mathrm{k}$ value decreased by 4,4 fold, indicating the effect of biological pretreatment on slowing down the decline in hydrolysis rate during enzymatic hydrolysis. Similar results have been reported by Yu et al. 2009.

Biological pretreatment leads to the degradation of lignin and consequently increased pore size in the substrate, which provides greater accessible surface area to cellulose. As depicted in Table 1, the degree of lignin removal change depends on the pretreatment time. As illustrated in Figure 4, there is a linear relationship between the lignin degradation and hydrolysis ratio $\left(\mathrm{R}^{2}=0,951\right)$. As lignin degradation increased from 0 (untreated) to $6,18 \%$ the hydrolysis ratio decreased from 2,2 to $6,62 \%$. Some reports have demonstrated the correlation between hydrolysis ratio and lignin degradation of 
biological pretreated lignocellulosic biomass (Wan and Li 2010, Nazarpour et al. 2013), which indicate the possibility of cellulose digestibility by preferential degradation of lignin.

Table 4. Kinetics parameters of enzymatic hydrolysis of untreated and fungal-treated rapeseed straw by P.chrysosporium based on Equation 7.

\begin{tabular}{|c|c|c|c|c|}
\hline $\begin{array}{c}\text { Pretreatment } \\
\text { time (day) }\end{array}$ & $\mathbf{V}_{\mathbf{0}}(\mathbf{\%} / \mathbf{h})$ & $\mathbf{K}$ & $\mathbf{R}^{2}$ & $\mathbf{S S E}$ \\
\hline $\mathbf{0}$ & 1,530 & 2,415 & 0,991 & 0,036 \\
\hline $\mathbf{5}$ & 2,114 & 1,368 & 0,996 & 0,040 \\
\hline $\mathbf{1 0}$ & 1,133 & 0,817 & 0,994 & 0,114 \\
\hline $\mathbf{1 5}$ & 1,136 & 0,547 & 0,997 & 0,095 \\
\hline
\end{tabular}

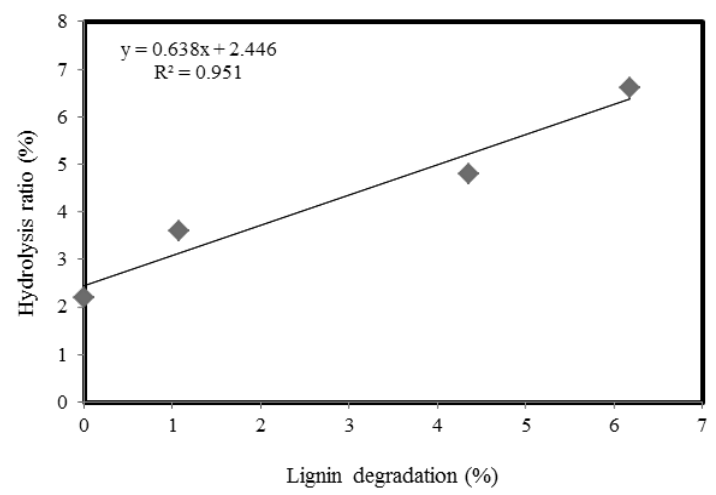

Figure 4. Effect of lignin degradation on the enzymatic hydrolysis of rapeseed straw pretreated by P.chrysosporium. Hydrolysis ratio (\%) was obtained after $56 \mathrm{~h}$ of enzymatic hydrolysis.

\section{CONCLUSIONS}

The results suggest that the enzymatic hydrolysis of the rapeseed straw can be enhanced by biological pretreatment with P.chrysosporium. The X-ray analysis exhibited higher crystallinity of all pretreated samples compared to samples in the control group. Nevertheless, the highest crystallinity of biological pretreated sample was observed after 15 days. It increased from $33,17 \%$ for the untreated rapeseed straw to $39,47 \%$ for the pretreated sample after 15 days. The lignin degradation by P.chrysosporium was confirmed using FTIR spectroscopy. The results of FTIR indicatedthe preferential nature of this white rot fungi. Scanning Electron Microscopy (SEM) showed structural changes in the pretreated rapeseed straw, such that the surface of pretreated rapeseed straw was partially broken and many pores were developed. In addition, the pretreatment slowed down hydrolysis rate during enzymatic hydrolysis, such that after 15 days, a 4,4-fold decrease in $\mathrm{k}$ value was observed.

\section{REFERENCES}

Ansari, Z.; Karimi, A.; Ebrahimi, S.; Emami, E. 2016. Improvement in ligninolytic activity of Phanerochaete chrysosporium cultures by glucose oxidase. Biochem Eng J Part B 105: 332-338.

Bari, E.; Mohebby, B.; Naji, H. R.; Oladi, R.; Yilgor, N.; Nazarnezhad, N.; Ohno, K. M.; Nicholas, D. D. 2018. Monitoring the cell wall characteristics of degraded beech wood by white-rot 
fungi: Anatomical, chemical, and photochemical study. Maderas-Cienc Tecnol 20(1):35-56.

Boonstra, M. J.; Rijsdijk, J. F.; Sander, C.; Kegel, E.; Tjeerdsma, B.; Militz, H.; Van Acker, J.; Stevens, M. 2006. Microstructureal and physical aspects of heat treatment wood. Part 1. softwoods. Maderas-Cienc Tecnol 8 (3): 193-208.

Camarero, S.; Martinez, M.; Martinez, A. T. 2014. Understanding lignin biodegradation for the improved utilization of plant biomass in modern biorefineries. Biofuels Bioprod Biorefin 8: 615-625.

Castoldi, R.; Bracht, A.; de Morais, G. R.; Baesso, M. L.; Correa, R. C. G.; Peralta, R. A.; Moreira, R. ; Polizeli, M.; de Souza, C. G.; Peralta, R. M. 2014. Biological pretreatment of Eucalyptus grandis sawdust with white-rot fungi: Study of degradation patterns and saccharification kinetics. Chem Eng J 258: 240-246.

Chandra, R. P.; Bura, R.; Mabee, W. E.; Berlin, A.; Pan, X.; Saddler, J. N. 2007. Substrate pretreatment: The key to effective enzymatic hydrolysis of lignocellulosics? Adv Biochem Eng Biotechnol 108: 67-93.

Deswal, D.; Gupta, R.; Nandal, P.; Kuhad, R. C. 2014. Fungal pretreatment improves amenability of lignocellulosic material for its saccharification to sugars. Carbohydr Polym 99: 264-269.

Dionisi, D.; Anderson, J. A.; Aulenta, F.; McCue, A.; Paton, G. 2015. The potential of microebial processes for lignocellulosic biomass conversion to ethanol: a review. $J$ Chem Technol Biotechnol 90 (3): 366-383.

Ferraz, A.; Parra, C.; Freer, J.; Baeza, J.; Rodríguez, J. 2000. Characterization of white zones produced on pinus radiata wood chips by ganoderma australe and ceriporiopsis subvermispora. World J Microb Biotechnol 16: 641-645.

Food and Agriculture Organization of the United Nations. FAO. 2016. Faostat. [online] Available from: $<\underline{\text { http://faostat3.fao.org/download/Q/QC/E }>\text {. [cited } 16 \text { February 2016] }}$

Geddes, C. C.; Peterson, J. J.; Roslander, C.; Zacchi, G.; Mullinnix, M. T.; Shanmugam, K. T.; Ingram, L. O. 2010. Optimizing the saccharification of sugar cane bagasse using dilute phosphoric acid followed by fungal cellulases. Bioresource Technol 101 (6): 1851-1857.

Ghasemzadeh, R.; Hamed Mosavian, M. T.; Karimi, A. 2015. Fungal Pretreatment of rapeseed straw by solid-state fermentation of Phanerochaete chrysosporium to produce reducing sugars. Int $J$ Biol Pharm Allied Sci 4 (8): 5711-5721.

Itoh, H.; Wada, M.; Honda, Y.; Kuwahara, M.; Watanabe, T. 2003. Bioorganosolve pretreatments for simultaneous saccharification and fermentation of beech wood by ethanolysis and white rot fungi. $J$ Biotechnol 103: 273-280.

Jeoh, T.; Ishizawa, C. I.; Davis, M. F.; Himmel, M. E.; Adney, W. S.; Johnson, D. K. 2007. Cellulase digestibility of pretreated biomass is limited by cellulose accessibility. Biotechnol Bioeng 98: 112-122.

Kim, T. H.; Lee, Y. Y. 2005. Pretreatment and fractionation of corn stover by ammonia recycle percolation process. Bioresour Technol 96: 2007-2013.

Kumar, A. G.; Sekaran, G.; Krishnamoorthy, S. 2006. Solid state fermentation of Achras zapota lignocellulose by Phanerochaete chrysosporium. Bioresour Technol 97: 1521-1528.

Kumar, R.; Mago, G.; Balan, V.; Wyman, C. E. 2009. Physical and chemical characterizations of corn stover and poplar solids resulting from leading pretreatment technologies. Bioresour Technol 100: 3948-3962. 
Li, S.; Li, J.; Hu, X.; Li, M.; Yan, Z.; Li, S.; Fan, C. 2013. Study on enzymatic saccharification of Suaeda salsa as a new potential feedstock for bio-ethanol production. J Taiwan Inst Chem Eng 44 (6): 904-910.

Li, X.; Kim, T. H.; Nghiem, N. P. 2010. Bioethanol production from corn stover using aqueous ammonia pretreatment and two-phase simultaneous saccharification and fermentation (TPSSF). Bioresour Technol 101 (15): 5910-5916.

López-Linares, J. C.; Romero, I.; Cara, C.; Ruiz, E.; Castro, E.; Moya, M. 2014. Experimental study on ethanol production from hydrothermal pretreated rapeseed straw by simultaneous saccharification and fermentationp. J Chem Technol Biotechnol 89 (1): 104-110.

Lu, X.; Zhang, Y.; Angelidaki, I. 2009. Optimization of $\mathrm{H}_{2} \mathrm{SO}_{4}$-catalyzed hydrothermal pretreatment of rapeseed straw for bioconversion to ethanol: Focusing on pretreatment at high solids content. Bioresour Technol 100: 3048-3053.

Margeot, A.; Hahn-Hagerdal, B.; Edlund, M.; Slade, R.; Monot, F. 2009. New improvements for lignocellulosic ethanol. Curr Opin Biotechnol 20 (3): 372-380.

Miller, G. L. 1959. Use of Dinitrosalicylic Acid Reagent for Determination of Reducing Sugar. Anal Chem 31 (3): 426-428.

Nazarpour, F.; Abdullah, D. K.; Abdullah, N.; Zamiri, R. 2013. Evaluation of Biological Pretreatment of Rubberwood with White Rot Fungi for Enzymatic Hydrolysis. Materials 6: 2059-2073.

Öhgren, K.; Bura, R.; Saddler, J.; Zacchi, G. 2007. Effect of hemicellulose and lignin removal on enzymatic hydrolysis of steam pretreated corn stover. Bioresour Technol 98: 2503-2510.

Ohmine, K.; Ooshima, H.; Harano, Y. 1983. Kinetic study on enzymatic hydrolysis of cellulose by cellulase from Trichoderma viride. Biotechnol Bioeng 25: 2041-2053.

Salvachúa, D.; Prieto, A.; López-Abelairas, M.; Lu-Chau, L.; Martínez, A. T.; Martínez, M. 2011. Fungal pretreatment: an alternative in second-generation ethanol from wheat straw. Bioresour Technol 102: 7500-7506.

Sedighi, M.; Karimi, A.; Vahabzadeh, F. 2009. Involvement of ligninolytic enzymes of Phanerochaete chrysosporium in treating the textile effluent containing Astrazon Red FBL in a packedbed bioreactor. J Hazard Mater 169 (1-3): 88-93.

Segal, L.; Creely, J.; Martin, A.; Conrad, C. 1959. An empirical method for estimating the degree of crystallinity of native cellulose using the x-ray diffractometer. Text Res $J$ 29: 786-794.

Sendich, E. N.; Laser, M.; Kim, S.; Alizadeh, H.; Laureano-Perez, L.; Dale, B.; Lynd, L. 2008. Recent process improvements for the ammonia fiber expansion (AFEX) process and resulting reductions in minimum ethanol selling price. Bioresour Technol 99: 8429-8435.

Shi, J.; Sharma-Shivappa, R. R.; Chinn, M.; Howell, N. 2009. Effect of microbial pretreatment on enzymatic hydrolysis and fermentation of cotton stalks for ethanol production. Biomass Bioenergy 33: $88-96$.

Shrestha, P.; Rasmussen, M.; Khanal, S. K.; Ometto III, A. P.; Vanleeuwen, J. H. 2008. SolidSubstrate Fermentation of Corn Fiber by Phanerochaete chrysosporium and Subsequent Fermentation of Hydrolysate into Ethanol. J Agric Food Chem 56: 3918-3924.

Singh, D.; Chen, S. 2008. The white-rot fungus Phanerochaete chrysosporium: conditions for the production of lignin-degrading enzymes. Appl Microbiol Biotechnol 81 (3): 399-417. 
Singh, D.; Zeng, J.; Laskar, D. D.; Deobald, L.; Hiscox, W. C.; Chen, S. 2011. Investigation of wheat straw biodegradation by Phanerochaete chrysosporium. Biomass Bioenergy 35: 1030-1040.

Sun, F.; Li, J.; Yuan, Y.; Yan, Z.; Liu, X. 2011. Effect of biological pretreatment with Trametes hirsuta yj9 on enzymatic hydrolysis of corn stover. Int Biodeterior Biodegrad 65 (7): 931-938.

Sun, Y.; Cheng, J. 2002. Hydrolysis of lignocellulosic materials for ethanol production: a review. Bioresour Technol 83 (1): 1-11.

Taniguchi, M.; Suzuki, H.; Watanabe, D.; Sakai, K.; Hoshino, K.; Tanaka, T. 2005. Evaluation of pretreatment with Pleurotus ostreatus for enzymatic hydrolysis of rice straw. J Biosci Bioeng 100 (6): 637-643.

Tozluoglu, A. 2016. The effects of boron derivatives as pretreatment chemicals for biodegradation of sunflower stalks. Maderas-Cienc Tecnol 18: 663-676.

Van Soest, P. J. 1963. Use of detergents in the analysis of fibrous feeds II: a rapid method for the determination of fibre and lignin. J Assoc Off Agr Chem 46: 829-835.

Wan, C.; Li, Y. 2010. Microbial pretreatment of corn stover with ceriporiopsis subvermispora for enzymatic hydrolysis and ethanol production. Bioresour Technol 101: 6398-6403.

Xu, C.; Ma, F.; Zhang, X.; Chen, S. 2010. Biological Pretreatment of Corn Stover by Irpex lacteus for Enzymatic Hydrolysis. J Agric Food Chem 58: 10893-10898.

Yamashita, Y.; Shono, M.; Sasaki, C.; Nakamura, Y. 2010. Alkaline peroxide pretreatment for efficient enzymatic saccharification of bamboo. Carbohydr Polym 79 (4): 914-920.

Yao, W.; Nokes, S. E. 2014. Phanerochaete chrysosporium pretreatment of biomass to enhance solvent production in subsequent bacterial solid-substrate cultivation. Biomass Bioenergy 62 (0): 100107.

Yu, H.; Guo, G.; Zhang, X.; Yan, K.; Xu, C. 2009. The effect of biological pretreatment with the selective white-rot fungus Echinodontium taxodii on enzymatic hydrolysis of softwoods and hardwoods. Bioresour Technol 100 (21): 5170-5175.

Yu, H.; Zhang, X.; Song, L.; Ke, J.; Xu, C.; Du, W.; Zhang, J. 2010. Evaluation of whiterot fungi-assisted alkaline/oxidative pretreatment of corn straw undergoing enzymatic hydrolysis by cellulase. J Biosci Bioeng 110: 660-664.

Zeng, J.; Singh, D.; Chen, S. 2011. Biological pretreatment of wheat straw by Phanerochaete chrysosporium supplemented with inorganic salts. Bioresour Technol 102: 3206-3214.

Zhang, J.; Ren, X.; Chen, W.; Bao, J. 2012. Biological pretreatment of corn stover by solid state fermentation of Phanerochaete chrysosporium. Front Chem Sci Eng 6 (2): 146-151.

Zhang, S.; Jiang, M.; Zhou, Z.; Zhao, M.; Li, Y. 2012. Selective removal of lignin in steamexploded rice straw by Phanerochaete chrysosporium. Int Biodeterior Biodegrad 75: 89-95.

Zhang, X.; Xu, C.; Wang, H. 2007. Pretreatment of bamboo residues with Coriolus versicolor for enzymatic hydrolysis. J Biosci Bioeng 104 (2): 149-151.

Zhao, X. B.; Wang, L.; Liu, D. H. 2008. Peracetic acid pretreatment of sugarcane bagasse for enzymatic hydrolysis: A continued work. J Chem Technol Biotechnol 83: 950-956.

Zhong, W.; Zhang, Z.; Qiao, W.; Fu, P.; Liu, M. 2011. Comparison of chemical and biological pretreatment of corn straw for biogas production by anaerobic digestion. Renew Energy 36 (6): 18751879. 